\title{
Erratum to: Model compression and simplification pipelines for fast deep neural network inference in FPGAs in HEP
}

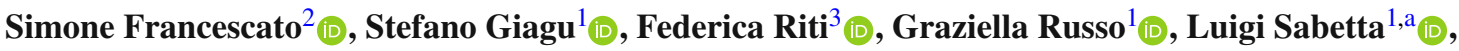 \\ Federico Tortonesi ${ }^{1}$ \\ ${ }^{1}$ Department of Physics, Sapienza University and INFN Sezione di Roma, 00185 Rome, Italy \\ 2 Department of Physics, Harvard University, Cambridge, MA 02138, USA \\ ${ }^{3}$ Department of Physics, ETH Zürich, 8092 Zurich, Switzerland
}

Published online: 3 December 2021

(C) The Author(s) 2021

Erratum to: Eur. Phys. J. C (2021) 81:969

https://doi.org/10.1140/epjc/s10052-021-09770-w

In this article the following acknowledgment was omitted:

This work was supported by the CHIST-ERA grant CHIST-ERA-19-XAI-009, by INFN and MIUR Italy.

The original article has been corrected.

Open Access This article is licensed under a Creative Commons Attribution 4.0 International License, which permits use, sharing, adaptation, distribution and reproduction in any medium or format, as long as you give appropriate credit to the original author(s) and the source, provide a link to the Creative Commons licence, and indicate if changes were made. The images or other third party material in this article are included in the article's Creative Commons licence, unless indicated otherwise in a credit line to the material. If material is not included in the article's Creative Commons licence and your intended use is not permitted by statutory regulation or exceeds the permitted use, you will need to obtain permission directly from the copyright holder. To view a copy of this licence, visit http://creativecomm ons.org/licenses/by/4.0/.

Funded by SCOAP ${ }^{3}$.

The original article can be found online at https://doi.org/10.1140/ epjc/s10052-021-09770-w.

a e-mail: 1.sabetta.g@gmail.com (corresponding author) 